This item was submitted to Loughborough's Research Repository by the author.

Items in Figshare are protected by copyright, with all rights reserved, unless otherwise indicated.

\title{
Support with caveats: advocates' views of the Theory of Formal Discipline as a reason for the study of advanced mathematics
}

PLEASE CITE THE PUBLISHED VERSION

http://dx.doi.org/10.1080/14794802.2017.1285720

\section{PUBLISHER}

(c) British Society for Research into Learning Mathematics. Published by Taylor \& Francis (Routledge)

\section{VERSION}

AM (Accepted Manuscript)

\section{PUBLISHER STATEMENT}

This work is made available according to the conditions of the Creative Commons Attribution-NonCommercialNoDerivatives 4.0 International (CC BY-NC-ND 4.0) licence. Full details of this licence are available at: https://creativecommons.org/licenses/by-nc-nd/4.0/

\section{LICENCE}

CC BY-NC-ND 4.0

\section{REPOSITORY RECORD}

Wainwright, Elaine, Nina Attridge, David Wainwright, Lara Alcock, and Matthew Inglis. 2019. "Support with Caveats: Advocates' Views of the Theory of Formal Discipline as a Reason for the Study of Advanced Mathematics". figshare. https://hdl.handle.net/2134/24201. 


\section{Support with caveats: Advocates' views of the Theory of Formal Discipline as a}

reason for the study of advanced mathematics

Elaine Wainwright ${ }^{\mathrm{a}}$, Nina Attridge ${ }^{\mathrm{b}^{*}}$, David Wainwright ${ }^{\mathrm{c}}$, Lara Alcock ${ }^{\mathrm{b}}$ and Matthew Inglis ${ }^{\mathrm{b}}$

${ }^{a}$ Department of Psychology, Bath Spa University, Bath, UK

${ }^{\mathrm{b}}$ Mathematics Education Centre, Loughborough University, Loughborough, UK

${ }^{\mathrm{c}}$ Department for Health, University of Bath, Bath, UK

*Corresponding author: Nina Attridge, Mathematics Education Centre, Schofield Building, Loughborough University, Loughborough, UK, n.f.attridge@lboro.ac.uk 


\begin{abstract}
The Theory of Formal Discipline (TFD) suggests that studying mathematics improves general thinking skills. Empirical evidence for the TFD is sparse, yet it is cited in policy reports as a justification for the importance of mathematics in school curricula. The study reported in this paper investigated the extent to which influential UK advocates for mathematics agree with the TFD and their views on the arguments and evidence that surround it. Quantitative and qualitative analysis of data from structured interviews revealed four themes: broad endorsement of the TFD; reference to supportive employment data; the possibilities that mathematics education might not always effectively develop reasoning and that study of other subjects might have similar effects; and concerns about causality and the extent of the evidence base. We conclude that advocates broadly support the TFD despite being aware of its limitations.
\end{abstract}

\title{
Keywords
}

Theory of Formal Discipline; mathematics education; thinking skills; policy; logical reasoning; conditional reasoning 


\section{Introduction}

It has long been assumed that people can be taught to think more rationally, and that mathematics is a useful tool to accomplish this. This view forms a part of what is known as the Theory of Formal Discipline (TFD): the idea that studying certain rigorous subjects, such as Latin, Greek or mathematics, can lead to the development of domain-general thinking skills, such as logical reasoning and critical thinking (Nisbett, 2009; Lehman, Lampert \& Nisbett, 1988). Smith, Langston and Nisbett (1992) describe this as "one of the oldest views about the nature of thought" (p. 1), stemming from Plato's theories of reasoning and education (see Plato, 375BC/2003). Historically, the TFD has been advocated by both mathematicians and philosophers. The philosopher John Locke, for instance, suggested that mathematics be taught to 'all those who have time and opportunity, not so much to make them mathematicians as to make them reasonable creatures’ (Locke, 1706, p. 20).

In recent years the TFD has been endorsed in a variety of policy documents in the UK and beyond. The influential Smith Report stated that as well as being important for its own sake, mathematics also 'disciplines the mind, develops logical and critical reasoning, and develops analytical and problem-solving skills to a high degree’ (Smith, 2004, p. 11). Vorderman’s (2011) report on mathematics education, commissioned by the governing Conservative Party, stated that 'mathematics is not only a language and a subject in itself, but it is also critical in fostering logical and rigorous thinking' (p.3) and that the 'analytical, logical and problem-solving skills which are acquired when studying mathematics have made mathematics graduates among the most employable of all university graduates and highly sought after in the workplace’ (p. 89). Walport’s (2010) policy report suggested that “[P]roblem solving abilities, perseverance and logic are [...] highly sought after and are commonly found 
in those with a high level of competency in mathematics” (p.185). While the policy reports quoted here do not give the TFD as the primary motivation for mathematics education, they do cite it as one reason for the importance of teaching mathematics.

Furthermore, both Stanic (1986) and Stanic and Kilpatrick (1992) argued that changes to the school-level mathematics curriculum in the US had been influenced by views related to the TFD. Stanic (1986) discussed how mathematics education became a distinct professional area in the 1890s, led by a humanist group, and was challenged in the 1930s by three other groups: the developmentalists, the social efficiency educators and the social meliorists. He describes the humanists as endorsing views closely related to the theory of formal discipline ${ }^{1}$ : “According to the humanists, mathematics should be taught because it is an important part of our Western cultural heritage and (at least for some of the humanists) because of its unique contribution to the development of an individual's reasoning ability.” (p.192). He specifically attributed this view to Young and Smith, leading mathematics education specialists at the turn of the century, who saw mathematics as "a vehicle for the development of reasoning power.” (p.193).”

Similar to the humanist view of mathematics education is the "public educator” ideology described by Ernest (1991). Of the five educational ideologies Ernest describes, the "public educator" is favoured and most akin to the TFD. Ernest quotes Freire's tenets of the public educator ideology, including that the aim of education is to achieve "a permanent critical approach to reality in order to discover it and discover the myths that deceive us and help to maintain the oppressing dehumanizing structures” (quoted in Dale et al, 1976, p 225). The public educator ideology in the context of mathematics suggests that an aim of mathematics is to help people become critical thinkers in the real world, with a particular application to 
issues of social justice. A conflicting ideology is the Old Humanist, which sees mathematics as intrinsically valuable and culturally important. In this view, knowledge is worthwhile for its own sake regardless of applications to the real world. To the Old Humanists, the TFD might be seen as an idea about the value and purpose of mathematics education regardless of its validity.

Positive views of the TFD are clearly present in the policy documents cited above, but these reports typically neither present direct evidence to support it nor problematize the extent to which senior advocates for mathematics agree about its truth. What, then, are the views of those who influence contemporary educational policy? Do they all endorse the TFD? To what extent are they aware and critical of the associated evidence base? This paper addresses these questions by reporting on interviews with advocates in the UK mathematics education policy community. To frame the work, we begin by reviewing relevant empirical research.

\section{Evidence on the TFD}

The TFD can be traced back to Plato, who suggested that 'Those who have a natural talent for calculation are generally quick at every other kind of knowledge; even the dull, if they have had an arithmetical training [...] become much quicker than they would otherwise have been' (Plato, 375B.C/2003, p. 256). Based on this, he recommended that we should 'encourage those who are to be the principal men of our state to go and learn arithmetic' (Plato, 375B.C/2003, p. 256).

Despite its long history, the TFD has been only minimally tested. It was not until the early $20^{\text {th }}$ century that Thorndike (1924) measured children's general intelligence before and after a year of schooling and found that students' subject choices had only a minor influence on changes in intelligence test scores: French, 
chemistry and trigonometry were associated with the largest, albeit small, improvements, while arithmetic, geometry and algebra were associated with improvements barely above zero.

Contrasting findings at higher educational levels have emerged more recently and in relation specifically to conditional reasoning skills. Reasoning about conditional 'if...then' statements is an important component of logical reasoning in general (Braine, 1978; Inglis \& Simpson, 2008), and is fundamental to mathematics in particular (Polya, 1954), and Lehman and Nisbett (1990) found evidence that studying mathematics at university level was associated with improved conditional reasoning skills. They tested US undergraduates in their first and fourth years on conditional reasoning as well as statistical and methodological reasoning, and found a correlation between number of mathematics courses taken and change in conditional reasoning behaviour across all majors $(r=.31)$, with a stronger effect for natural science majors $(r=.66)$.

Conditional reasoning ability was also investigated by Inglis and Simpson (2009), who compared mathematics and non-mathematics undergraduates in the UK system in which students apply to study only one or two main subjects at university. They gave both groups of undergraduates a 32-item abstract Conditional Inference Task and observed that the mathematics undergraduates performed significantly better than the comparison undergraduates, even after controlling for differences in intelligence (measured using the AH5 test, Heim, 1968). However, when the mathematics students were re-tested at the end of their first year of study, there was an average improvement in conditional reasoning performance of only $1.8 \%$, which did not approach significance. The lack of improvement left two possible explanations for the initial difference between groups on entry to university: either post-compulsory 
but pre-university specialisation in mathematics was responsible, or those who are already better at conditional reasoning are disproportionately filtered into studying university-level mathematics.

These possibilities were disentangled by Attridge \& Inglis (2013), who investigated the development of conditional reasoning skills in mathematics and nonmathematics A-level ${ }^{2}$ students. Attridge and Inglis found no between-group differences in conditional reasoning at the beginning of A-level, but after one year the mathematics students' reasoning had significantly improved whereas the nonmathematics students' reasoning had not. This contradicts the filtering hypothesis and suggests that A-level mathematics influences conditional reasoning skills, in support of the TFD.

Thus the evidence for the TFD is limited. There is minimal evidence on the influence of mathematics on thinking skills in compulsory education; A-level mathematics appears to improve conditional reasoning skills (Attridge \& Inglis, 2013); and on undergraduate mathematics the evidence is mixed (Inglis \& Simpson, 2009; Lehman and Nisbett, 1990). Nevertheless, the TFD has been used in several recent policy reports as one reason (among many others) to argue for mathematics to be prioritised in the UK National Curriculum, indicating that some advocates at least believe it to be justified. Our aim in the current paper is to explore this issue, investigating current advocates views on the TFD. To accomplish this, we use data from interviews in which advocates were asked both to rate the extent to which they would expect mathematical training to improve students’ performance on reasoning tasks, and to respond to explicit claims made in relation to the TFD.

\section{Method}




\section{Participants and data collection}

Semi-structured interviews were conducted with eight influential advocates in the UK mathematics education community. We sampled purposively (Patton, 2002), emailing to invite participation from expert individuals who had recently contributed to an organisation with significant influence over mathematics education policy. We have removed some affiliations for anonymity, but the participants included former advisers to the Higher Education Authority; a government minister with influence on educational policy, and university senior managers. In total, the sample was composed of six influential academic mathematicians, together with one politician and one academic mathematics educator (see Table 1). Whilst there are therefore some contrasting elements between participants' roles, the common strand between interviewees is that they all have broader roles within mathematics education, and some influence on policy. This sample represents a particular group of advocates for mathematics education; we acknowledge that advocates for STEM subjects more generally may be very different to this group.

Participants were approached sequentially and after informed consent was gained, analysis was conducted in an ongoing manner according to the principles of constructivist grounded theory methods (Glaser and Strauss, 1967; Charmaz, 2006). We followed questions suggested by Charmaz (2006) to determine when theoretical saturation had been reached, asking what sense we had made of comparisons between data, and how these illuminated our categories. For example, “endorsement of TFD” was a category pertinent to the analysis of all interviews and the data were not saturated in this category until we had considered what this endorsement meant to participants, how they justified and critiqued it and how it affected other issues (such as unease regarding quality of the evidence base for the TFD). Recruitment was 
curtailed when no significant new themes were emerging, after eight interviews. This is a small sample but it is possible to find that no new insights are emerging at such a point (Baker and Edwards, 2012). The size and sampling strategy limit the generalisability of findings. However, we are not claiming representativeness: rather, we considered a small scale, exploratory in-depth qualitative study appropriate in order to begin to investigate advocates’ views about the TFD.

Interviews were conducted between January and May 2011 and lasted on average 56 minutes (range: 40 to 74 ).

[Insert Table 1 near here]

\section{Procedure and materials}

Participants took part individually, in a one-to-one meeting with a researcher. Interviews were audio-recorded and transcribed. The interview schedule opened with invitations to discuss quotations about the TFD (see Figure 1). Participants then used a Likert scale (1 - disagree to 5 - agree) to rate the extent to which they thought that studying post-compulsory mathematics would improve performance on 13 reasoning tasks: the abstract conditional inference task (Evans, Clibbens \& Rood, 1995), a belief bias syllogisms task (Evans, Barston \& Pollard, 1983), Raven’s advanced progressive matrices (Raven, Raven \& Court, 1998), the cognitive reflection test (Frederick, 2005), the four card selection task (Wason, 1968), the THOG task (Wason \& Brooks, 1979), the argument evaluation task (Stanovich \& West, 1997), the Watson Glaser evaluation, interpretation and assumptions tasks (Watson \& Glaser, 1964), a problemsolving task (Knoblich, Ohlsson \& Raney, 2001), a plausible estimation task (Swan \& Ridgway, 2010) and a statistical reasoning task (Stanovich \& West, 1998). All 
tasks appear in the Appendix (with the exception of Raven’s Matrices due to copyright). We selected a range of tasks, including abstract formal ones (e.g. abstract conditional inference) and contextual formal ones (e.g. belief bias syllogisms), which are more plausibly related to the TFD, and contextual informal ones (e.g. plausible estimation), which are less clearly related to the TFD, to investigate where the boundaries of the TFD would be in our participants' opinions.

[Insert Figure 1 near here]

\section{Interview analysis}

The interview data were analysed in NVivo 10 software (QSR International Pty Ltd., 2012) to facilitate the application of constructivist grounded theory methods. Major principles of these methods are that (i) individuals' realities have categories which we can understand and broadly classify; (ii) as a social situation, the research process influences the data collected; (iii) as researchers we simply offer an interpretation of the data (Charmaz, 2006). Grounded theory uses codes as conceptual labels applying to phenomena indicated by the data, and initial codes are carefully considered to determine those that render the interpretation of the data most coherent; these become focused codes, effectively thematic headings (Glaser and Strauss, 1967). In this study, whilst acknowledging researchers' influence on shaping analysis, we attempted to code data without fitting them into analytic preconceptions. One researcher constructed initial codes, listed these with central illustrative verbatim quotations, scrutinised and ordered them into analytical hierarchies, and thus established core themes. Another team-member took a percentage of the quotations and grouped them into the previously identified core themes, then differences were 
debated until the coders agreed. We were alert to deviant cases, testing them against the main themes, to ensure a thorough account of the data was attained (Green and Thorogood, 2004). For example, an initial code was “ambivalence about the TFD”; during the constant comparison of data, this code was split into two core themes, so that we now discuss participants' endorsement of the TFD separately from their awareness of quality issues with the evidence base. One participant was deviant in the sense they were willing to explicitly refute research evidence if it did not fit their view of the TFD's usefulness (discussed below). However, there was broad overlap in the responses across all participants. We have not quantitatively summarised the breadth of occurrence as this suggests a representativeness which can ignore how themes' strengths were also expressed by different degrees of fervour (Wenger, 1988; Gabe et al, 2002). In the bulk of the Results section we organise our presentation according to these themes, first presenting key quotations with minimal commentary and then providing a deeper analysis linking the themes together. We begin the Results, however, by providing a brief quantitative analysis of the ratings part of the interview.

\section{Results}

\section{Ratings}

Participants expressed a range of views on the extent to which postcompulsory mathematical study would be expected to influence performance on the 13 general reasoning tasks. Median ratings for the tasks ranged from 2 to 5, and are presented in Table 2. The ratings for each task were compared to 3 ('neither agree nor disagree') using a Wilcoxon signed rank test. All but four tasks (problem-solving, argument evaluation, Watson Glaser evaluation and Raven’s Matrices) were rated significantly above 3 ( $p$ s $<.030$, see Table 2 ), indicating that participants expected 
studying mathematics to improve performance on the majority of the tasks.

Interestingly, the tasks that participants expected performance to be improved on were quite varied; from formal to informal and abstract to contextual, including the abstract conditional inference task, the plausible estimation task, and the Watson Glaser recognising assumptions task. This provides a first indication that the participants did, to some extent, endorse the TFD: they expected mathematical study to improve at least some general reasoning skills.

[Insert Table 2 near here]

\section{Interview theme: Endorsement of the TFD}

Participants' views on the TFD were varied and nuanced both across the group and within individual statements. Nevertheless, all participants gave several clear endorsements of the TFD, citing specific transferrable skills that they believed were developed by mathematical study. These skills included: abstract thinking; mental modelling of complex problems; considering all possible solutions to a problem; and structuring arguments rationally.

Participant 4:

I believe that that ability to learn, to control and manipulate abstract ideas in a logical and analytical way, I believe that is a process you do get better at as you do more mathematics.

Participant 5:

[I] expect overall maths students at whatever level to do, to do better [at problem-solving]. Because I would expect them to be able to actually carry out a systematic process. 
Participant 2 (considering the Wason Selection Task, which involves card turning):

Yes, I think [mathematics] would help with that because you consider all possibilities before you turned it over, and that's what you're used to doing in maths; you're thinking of all the possibilities - and do I need to do that? So I think maths would help with that.

Participant 1:

I think without any doubt [mathematics] probably does give you some structure to the way you think about things that perhaps some other people that haven't had some sort of mathematical training don't have...And without any doubt I do believe that mathematical training gives you a process for going about problem-solving.

Some participants defended the TFD on the grounds that non-mathematicians can exhibit inferior analytical skills.

Participant 1:

In conversations that I've had with people who are not mathematical they can argue in very odd ways sometimes. I'm not saying you wouldn't see it with mathematicians but I have seen it with people who are not mathematically trained.

Comments like all of these were common across the interviews, and arose in response to both the rating task and the open-ended questions. They provide more detailed evidence that the participants endorsed the TFD: they explicitly stated that they expected mathematical study to improve skills in both detailed reasoning and higher-level structuring of problem solving activity.

Interview theme: Mathematics and employability 
Several participants argued in favour of the TFD in an indirect way, citing the fact that employers value mathematics because it improves critical and logical skills which then translate to problem-solving in the workplace.

Participant 1:

...the country wants people who can look at these real problems and extract something sensible from this mess of real world data, do something useful with it to get some hopefully sensible answers out of it...And obviously you can do that in any walk of life. But I think that the maths training is what gives you the ability to do that.

Participant 5:

...it's quite clear that people outside the maths community agree [with the value of mathematics]...when the leading finance houses are looking to recruit people they recruit people with maths PhDs or physics PhDs. As opposed to people with business studies PhDs.

Whether employers value mathematicians for their general critical and logical skills, or because they possess knowledge of specific procedures, for example, modelling skills, are not mutually exclusive possibilities - good modellers need to be critical and logical, and criticality and logical thought might be enhanced by the ability to build good models. The participants collectively gave a sense of the subtleties of this argument. Some acknowledged that the formal critical and logical skills encouraged by studying mathematics are not necessarily the same as those required in the workplace but are closely linked, so that studying mathematics makes students valuable and capable employees.

Participant 7: 
I think people who have got a good quality mathematics degree well, they're in demand from all sorts of employers and not because they need their students to know about group theory or metric spaces but because they can do these things and obviously I'm kind of relying on just the fact that they keep employing them as being evidence that they are useful but I would imagine that if I was an employer and I needed people who were going to be logical, critical, analytical and be able to solve problems and I saw somebody who had a good class maths degree I think they would be a good bet.'

\section{Participant 5:}

An awful lot of jobs which don't have any overtly mathematical sort of elements to them are actually about using models. And a lot of them are spreadsheet models but you are putting data in and you are getting answers out and you, the user, are expected to make judgments about the reasonableness of the answer or to notice when a notice is completely off the rails and are meant to then actually make decisions sort of interpret them...in terms of making a decision about whether you repair something or whether you change the setting on a production machine or whatever...And so you know mathematics is contributing and...it's not necessarily critical thinking and logical reasoning it's, it's perhaps more on the problem-solving, modelling side of things...But, certainly a lot of the work that's been done recently in terms of looking at people in the workplace is saying that there is a lot of hidden maths and that, that the people...As they are carrying it out don't actually identify it as maths but when we...look at what they're doing we can identify them as actually carrying out mathematical thinking and...using mathematical skills. 
Participant 8:

...undoubtedly, in practice, out there it's used as a way of sorting out people and these are very hardnosed finance people and business people... and they use mathematics as a sieve. Now, they might not know why but it presumably has worked quite well.

This last point is perhaps more cynical but it does relate to the broader issue that in Western societies, high mathematical performance is sometimes viewed as a proxy measure for general intelligence or capability. Given the limited available evidence, this is not unreasonable: Inglis and Simpson (2009) did find that undergraduate mathematics students entered university with higher IQ measures than students in their comparison group. But it calls into question the value of the indirect employability argument as support for the TFD: mathematics students might be employable because they had good general thinking skills before they began their studies rather than because they developed them during those studies. Of course, the points the participants made about modelling have a different status, but even they are limited by real-world considerations, as noted next.

\section{Interview theme: Limitations of the TFD}

No participant completely disagreed with the TFD but most did make comments about its limitations, citing real world factors that influence how one learns and employs critical and logical skills. Some cited the simple point that a person who is capable of employing strong logical reasoning might not always do so.

\section{Participant 7:}

In my experience being good at maths wouldn't make you better at doing this [statistical reasoning/admissions task]...the skills that you develop from doing maths are far outweighed by, in my experience, all sorts of things that come to 
bear when you have to make such a decision. Gut feeling, money...Does the Department need any more dosh? Whether the person, whether the disagreement, you know personalities get in the way but these things are not necessarily relevant, I don't know...you can be perfectly capable of logical reasoning and still be capable of making an irrational decision.'

Some recognised pedagogical issues, noting that different programmes might focus on different skills, and that some teacher intentions might be subverted by learner actions if a syllabus allows students to succeed without really engaging with the intellectual content.

Participant 7:

I think it's possible to pass a maths degree, particularly a joint honours maths degree, without developing many of these [logical and critical reasoning skills] to a particularly high level.

Participant 8:

I'm reluctant to give a causal claim because... when you say 'mathematics training disciplines', I'm an educator, it depends what the bloomin' training is. It depends on what mathematics you've done.

Participant 5:

If maths graduates aren't doing better on these [tasks] than non-maths graduates then I yeah I think we are doing something wrong.

Many participants thought that whilst the TFD is reasonable, studying other disciplines might be as good or even better for training students in certain skills, particularly those associated with verbal reasoning.

Participant 5: 
'I would expect physics students to do better than maths students on a question like this [plausible estimation] because they are much more used to dealing with imprecision and making reasonable estimates for things that they don't always know. Whereas you know in A-level maths you never, there is never a requirement to sort of put in something reasonable because you always know what it is exactly.

Participant 2:

I mean things like somebody that's doing a programming degree I would imagine it's very, very logical there, so potentially there are other tools and some of them may be better. I don't know that maths is necessarily the best to teach logical thinking.

Participant 1:

I think you know if you're going to try and you know if you're going to take say for example the study of anatomy seriously and you want to know where all the blood vessels go and what serves what in the body I mean that's quite a deep analytical process to know what affects what in the body isn't it? So I would imagine that somebody who'd done a thorough study of something like that... had developed very logical and critical reasoning skills.

Participant 7:

I think if I wasn't a mathematician I'd find [belief bias syllogisms task] much easier to answer. I mean I'm trying to apply a logical reasoning to this question and this task. I can believe that you can be really good at mathematics and find this task really rather difficult because you are trying to make some assumptions about the person who said it. 
These quotations show that participants did not necessarily privilege mathematics above other subjects, although, as evidenced by their hedging ('I expect' and 'I think' rather than 'I know') many were concerned about their ability to comment on other disciplines. Several stated within the same interview that although they think that maths may be better at teaching certain skills, it is very difficult to tell for certain at the moment. Some were comfortable with this state of affairs, e.g. Participant 2 stated: 'so I don't feel uncomfortable about it [making TFD claims on a prospectus], and it's a kind of accepted thought really nowadays isn't it, that that's what is going on.' Others probed for more evidence, discussed below.

\section{Interview theme: Causality and evidence}

As might be expected from highly educated individuals, participants were alert to the difficulties associated with disentangling cause and effect: most discussed the possibility that there is simply a filtering effect in operation.

\section{Participant 5:}

'I would say that the reason...why students are good at maths and therefore tend to study it is because they have got these sorts of skills that enable them to, to recognize patterns that being something that fundamentally underlies a lot of mathematics. So, I'm not sure that, that doing maths A-level would have developed these skills. But the fact that you have got these skills makes, I would suggest makes you more likely to have done maths A-level in the first place.'

Participant 2:

What I'm not clear about here is the chicken and egg situation, so I'm not clear whether or not people that go into maths are already logical. 
Some participants were nevertheless inclined to defend the TFD, and were reluctant to engage with the idea that it might lack a strong evidence base as they were worried about reducing perceptions of the value of mathematics. When asked how they would respond if there was little evidence for the TFD, some expressed nervousness or were inclined to seek extra-mathematical reasons why the evidence might not exist.

Participant 4:

It's a very important question [whether the TFD is accurate]. It makes one a bit nervous in case the answer is no. [When asked for a reaction to the possibility that the current research team's work could undermine the TFD] I think we might well suppress your evidence by ignoring it.'

This was the most extreme response to the notion that the TFD may not be entirely accurate. More typical were responses that began to explain a lack of evidence by considering that the nature of mathematical learning could be the issue: Participant 8:

Is it that too much is being done by routine or by rote or by spotting the exam question and not really getting to grips with actually doing maths? It sounds a bit of an excuse but that's what my reaction would be.

Nearly all participants were aware that they were evaluating the TFD using exactly the kind of personal reasoning that the TFD is supposed to ameliorate against. The two quotations below are typical of those that arose across the interviews.

Participant 6:

I am quite a firm supporter of it [TFD] really...it's just my own experience of studying the subject really'

Participant 4: 
I'm finding it's difficult for me to answer these saying what people with a maths degree would have and to separate that from what I would find difficult'.

It is naturally very difficult to put aside one’s personal knowledge when discussing a concept (e.g. Seidman, 1998; Charmaz, 2000, 2006; Henwood and Pidgeon, 2006) and it is interesting that these participants who had studied mathematics to a high level still find it so, even when debating whether studying mathematics makes one more able to carry out such 'putting aside'. To what extent this might matter - especially if mathematics education advocates are aware how strongly they are being influenced by their own experiences - is another question, beyond the scope of the current study but worth of consideration by future work on both the evidence base for the TFD and what to do with this evidence.

\section{Summary}

Semi-structured interviews with eight expert participants allowed us to draw out four themes in relation to the extent to which the TFD is endorsed by mathematics education advocates. These were: broad endorsement of the TFD, indirect evidence via employability of mathematics graduates, limitations of the TFD (personal and pedagogical factors that might restrict its accuracy), and views on causality and evidence. We discuss each of these themes in turn before drawing them together and considering the implications of our findings.

Firstly, we identified unambiguous endorsements of the TFD across all of our interviews. Participants justified these endorsements by focusing on the subject knowledge undergraduates gain, combined with the benefits of the training and practice they receive in abstract reasoning, logical deduction and problem-solving. They did not believe it had universally large effects: they collectively rated 
mathematics as more supportive of some types of reasoning development and less obviously linked to others. But they did clearly believe that post-compulsory mathematical study supported the development of general reasoning skills across at least some task types.

Secondly, many participants spontaneously considered other evidence for the value of post-compulsory mathematical study, usually via objective data showing positive employment patterns for mathematics undergraduates. Some explicitly linked workplace success to mathematical skills, stating that many of the latter are directly transferable to a wide variety of jobs. Others argued that whilst many jobs may not use mathematical subject knowledge directly, mathematics graduates are highly valuable because their skills enable transfer of generic reasoning ability and problemsolving. At least some were aware, however, that this argument did not directly justify the TFD: valuing mathematics graduates' skills is not necessarily the same as valuing their training.

Thirdly, this point about mathematical training was elaborated upon by the participants' comments on possible limitations of the TFD. They noted that real world constraints, such as financial and political pressures, can impede rationality, that people capable of reasoning logically might fail to do so, and that mathematics might not be special: other disciplines might also teach skills in logical reasoning, and might even be of more value for at least some types of verbal problem.

Fourthly and finally, there was substantial ambivalence about causality and evidence in relation to the TFD. Participants were concerned about ascribing causation when it could be the case that people who are already good at reasoning are naturally and disproportionately filtered in to studying mathematics; in this respect their comments reflect issues raised in the research literature, as discussed in Section 
2. Some were also concerned about the extent to which the TFD is really justified.

They felt they could not evaluate other disciplines’ contributions to reasoning skills as well as they could reflect upon those of their own subject, and they recognized that as mathematically trained people they were prejudiced: they wanted to agree with the TFD. Some were discomfited by the suggestion that the TFD might be based on little evidence: they expressed unease that there might be evidence against it and, rather than consider that it might be inaccurate, were inclined to suggest that this evidence might be flawed or that syllabi may not allow sufficient practice of the right kind of skills.

\section{Discussion}

There has long been support for the idea that studying mathematics improves reasoning skills: the TFD has stood effectively unchallenged for centuries in philosophical treatises and for decades in educational policy documents. There is no doubt that it has face validity in contemporary education: our participants offered thoughtful and nuanced commentary on its likely accuracy, but all broadly agreed with the central claim.

We do not seek in this paper to suggest that the TFD is fundamentally incorrect or that our participants are unreasonable to believe it. Indeed, these interviews took place at the beginning of our own work in this area, and (as noted in the Section 2) our investigation of conditional reasoning in A-level students did demonstrate an improvement for those studying mathematics: mathematics and English literature A-level students did not differ on a conditional reasoning task at the start of post-compulsory education, but the mathematics students improved over their first year of study while the English students did not (Attridge \& Inglis, 2013). This 
suggests that mathematical study aids the development of at least this type of reasoning; that it does more than filter in 'good reasoners'.

We also recognise the limitations of our study: its sample size and sampling strategy limit the transferability of findings, and having a participant body composed of volunteers arising from purposive sampling may lead to systematic bias (Farmer and Lawrenson, 2004). Our participants immersed themselves in the interviews, providing thorough responses in their commitment to the research, and we have provided a description of participants' contexts so that readers may assess whether the findings are applicable to their areas of interest (Patton, 2002). But it remains possible that there exist individuals in similar positions in the UK or internationally who would be considerably more sceptical about the TFD or who would raise different questions about its limitations. Our sample represents a particular group of advocates for mathematics education only and we note that engineering or STEM advocates more generally might be very different to this group.

What we do want to do is to highlight the fact that big educational claims are sometimes made on the basis of very little evidence, and that the sweeping nature of claims like the TFD might in fact mask a host of interesting questions about the details of knowledge development. It is quite plausible, for instance, that different mathematical topics, pedagogies or cultures support the development of different general reasoning skills: perhaps the study of core topics in A-level mathematics improves conditional reasoning, but other topics have better effects for this or other types of task. For example, in Cyprus where the 16-18 mathematics curriculum has a substantial deductive geometry component, students’ abstract conditional reasoning skills improved in line with the normative model of the conditional to a greater extent than in A-level students in the UK (Attridge, Doritou \& Inglis, 2015; Attridge \& 
Inglis, 2013). The Cypriot students also showed a reduction in belief bias on a thematic syllogisms task (Attridge, Doritou \& Inglis, 2015). Possibilities of this nature should truly interest mathematics education advocates, who could use evidence to provide detailed recommendations about preparation that might benefit students with different existing skills and different career aspirations. Our findings also relate to the ideologies of mathematics education proposed by Ernest (1991) and perhaps suggest that at least some advocates implicitly endorse a public educator view of mathematics. At present there is no reason to abandon belief in the TFD, but there is compelling reason to pick apart its components and work towards research-informed curriculum recommendations.

In conclusion, it seems that there is still support for the TFD in the UK mathematics education policy community, but that advocates are aware of its limitations. Our participants also raised and expressed interest in open research questions, such as which areas of mathematics are most effective at developing reasoning skills, how effective other subjects like physics and philosophy are in developing reasoning skills, and whether some curricula might actually reduce the development of reasoning skills by focusing on rote learning. These questions provide mathematics education researchers with a rich source of inspiration for future investigations. 


\section{Acknowledgments}

This work was supported by a Royal Society Worshipful Company of Actuaries Research Fellowship to Matthew Inglis. 


\section{Endnotes}

1. Although not actually using that term.

2. A-levels are optional two-year courses taken after compulsory education ends at the age of 16 in the UK; students usually take three or four A-levels in chosen subjects and many students study no mathematics at this stage. 


\section{References}

Attridge, N. \& Inglis, M. (2013). Advanced Mathematical Study and the

Development of Conditional Reasoning Skills. PLoS ONE 8(7): e69399. doi:10.1371/journal.pone.0069399

Attridge, N., Doritou, M. \& Inglis, M. (2015). The development of reasoning skills during compulsory 16 to 18 mathematics education. Research in Mathematics Education, 17 (1), pp. 20-37.

Baker, S., Edwards, R. and Doidge, M. (2012) How many qualitative interviews is enough?: Expert voices and early career reflections on sampling and cases in qualitative research. National Centre for Research Methods Review Paper.

Braine, M. D. S. (1978). On the relation between the natural logic of reasoning and the standard logic. Psychological Review, 85, 1-21.

Charmaz, K. (2000). Constructivist and Objectivist Grounded Theory. Handbook of Qualitative Research (N. K. Denzin \& Y. Lincoln, eds), $2^{\text {nd }}$ edition. Thousand Oaks, CA: Sage, pp. 509-535.

Charmaz, K. (2006). Constructing Grounded Theory: A Practical Guide Through Qualitative Analysis. London: Sage.

Dale, R., Esland, G. and MacDonald, M. (1976). Schooling and Capitalism. London: Routledge and Kegan Paul.

Ernest, P. (1991). The Philosophy of Mathematics Education. Routledge Falmer.

Evans, J. St. B. T., Barston, J. L., \& Pollard, P. (1983). On the conflict between logic and belief in syllogistic reasoning. Memory \& Cognition, 11(3), 295-306.

Evans, J. St. B. T., Clibbens, J., \& Rood, B. (1995). Bias in conditional inference: implications for mental models and mental logic. The Quarterly Journal of Experimental Psychology, 48(3), 644-670. 
Farmer, R., \& Lawrenson, R. (2004). Lecture Notes: Epidemiology and Public Health Medicine, $5^{\text {th }}$ edition. Oxford: Blackwell.

Frederick, S. (2005). Cognitive reflection and decision making. Journal of Economic Perspectives, 19, 25-42.

Gabe, J., Bury, M. \& Ramsay, R. (2002). Living with asthma: The experiences of young people at home and at school. Social Science and Medicine, 55 (9), 1619-1633.

Glaser, B., \& Strauss, A. (1967). The Discovery of Grounded Theory; Strategies for Qualitative Research. Chicago, IL: Aldine.

Green, J., \& Thorogood, N. (2004). Qualitative Methods for Health Research. London: Sage.

Heim, A. W. (1968). Manual for the AH5 group test of high-grade intelligence. National Foundation for Educational Research.

Henwood, K., \& Pidgeon, N.F. (2006). Grounded Theory. Research Methods in Psychology (G. Breakwell, S. Hammond, C. Fife-Shaw \& J. Smith eds), $3^{\text {rd }}$ edition. London: Sage.

Inglis, M., \& Simpson, A. (2008). Conditional inference and advanced mathematical study. Educational Studies in Mathematics, 67(3), 187-204.

Inglis, M., \& Simpson, A. (2009). Conditional inference and advanced mathematical study: Further evidence. Educational Studies in Mathematics, 72(2), 185-198.

Inhelder, B. \& Piaget, J. (1958). The growth of logical thinking from childhood to adolescence. New York: Basic Books.

Johnson-Laird, P. N. (2008). How We Reason. Oxford: Oxford University Press.

Knoblich, G., Ohlsson, S., \& Raney, G. E. (2001). An eye movement study of insight problem-solving. Memory \& Cognition, 29, 1000-1009. 
Lehman, D. R., Lampert, R. O., \& Nisbett, R. E. (1988). The effects of graduate training on reasoning: Formal discipline and thinking about everyday-life events. American Psychologist, 43, 431.

Lehman, D. R. \& Nisbett, R. E. (1990). A longitudinal study of the effects of undergraduate training on reasoning. Developmental Psychology, 26, 952-960.

Locke, J. (1971/1706). Conduct of the Understanding. New York: Burt Franklin.

Neisser, U. (1967). Cognitive Psychology. New York, NY: Meredith.

Nisbett, R. E. (2009). Can Reasoning be Taught? Cambridge, MA: American Academy of Arts and Sciences.

Patton, M. Q. (2002). Qualitative Research and Evaluation Methods, $3^{\text {rd }}$ edition. Newbury Park, CA: Sage.

Piaget, J. (1970). Piaget's Theory. Carmichael's Manual of Child Psychology (P. Mussen ed). New York: Wiley.

Plato. (2003/375B.C.). The Republic (D. Lee, Ed.). London: Penguin.

Polya, G. (1954). Induction and analogy in mathematics. New Jersey: Princeton University Press.

QSR International Pty Ltd. (2012). NVivo qualitative data analysis software; version 10.

Quality Assurance Agency for Higher Education. (2007). Mathematics, statistics and operational research. Retrieved $18^{\text {th }}$ November 2014 from http://www.qaa.ac.uk/en/Publications/Documents/Subject-benchmarkstatement-Mathematics-statistics-and-operational-research.pdf.

Raven, J., Raven, J. C., \& Court, J. H. (1998). Manual for Raven's Progressive Matrices and Vocabulary Scales. Section 4: The Advanced Progressive Matrices. San Antonio, TX: Harcourt Assessment. 
Seidman, S. (1998). Contested Knowledge; Social Theory in the Postmodern Era, $2^{\text {nd }}$ edition. Oxford: Blackwell.

Sfard, A. (1998). A mathematician's view of research in mathematics education: an interview with Shimshon A. Amitsur. Mathematics Education as a Research Domain: A Search for Identity (A. Sierpinska \& J. Kilpatrick eds). Dordrecht: Kluwer, pp. 445-458.

Smith, A. (2004). Making mathematics count: The report of Professor Adrian Smith's inquiry into post-14 mathematics education. London: The Stationery Office.

Smith, E. E., Langston, C., \& Nisbett, R. E. (1992). The case for rules in reasoning. Cognitive Science, 16, 1-40.

Stanic, G. M. A. (1986). The growing crisis in mathematics education in the early twentieth century. Journal for Research in Mathematics Education, 17, 190205.

Stanic, G. M. A., \& Kilpatrick, J. (1992). Mathematics curriculum reform in the United States: A historical perspective. International Journal of Educational Research, 17, 407-417.

Stanovich, K. E. (2009). Distinguishing the reflective, algorithmic, and autonomous minds: Is it time for a tri-process theory? In two minds: Dual processes and beyond (J. St. B. T. Evans \& K. Frankish eds). Oxford: Oxford University Press, pp. 55-88.

Stanovich, K. E., \& West, R. F. (1997). Reasoning independently of prior belief and individual differences in actively open-minded thinking. Journal of Educational Psychology, 89, 342.

Stanovich, K. E., \& West, R. F. (1998). Individual differences in rational thought. Journal of Experimental Psychology: general, 12, 161-188. 
Swan, M. \& Ridgway, J. (2010). Plausible Estimation Tasks. Field Tested Assessment Learning Guide.

Thorndike, E. L. (1924). Mental discipline in high school studies. The Journal of Educational Psychology, 15, 1-22.

Thorndike, E. L. \& Woodworth, R. S. (1901). The influence of improvement in one mental function upon the efficiency of other functions. Psychological Review, 8, 247-261.

Vorderman, C. (2011). A world-class mathematics education for all our young people. Retrieved November 242014 from http://www.tsmresources.com/pdf/VordermanMathsReport.pdf

Wason, P. C. (1968). Reasoning about a rule. Quarterly Journal of Experimental Psychology, 20(3), 273-281.

Wason, P. C., \& Brooks, P. G. (1979). THOG: The anatomy of a problem. Psychological Research, 41, 79-90.

Watson, G., \& Glaser, E. (1964). Watson - Glaser Critical Thinking Appraisal - UK Edition. London: Pearson.

Walport, M. (2010). Science and mathematics secondary education for the 21st century: Report of the Science and Learning Expert Group. London: Crown.

Wenger, G.C. (1988). Old people's health and experiences of the caring services. The institute of human ageing. Occasional Paper, Liverpool: Liverpool University Press. 


\section{Appendix.}

Task examples given to participants.

\section{Conditional Inference Task}

Aim: To assess whether participants are able to determine whether a conclusion follows from an (abstract) conditional statement and premise.

Instructions: Each problem concerns an imaginary letter-number pair and contains an initial statement or rule which determines which letters may be paired with which numbers. The task in each case is to decide whether or not the conclusion necessarily follows from the statements. A conclusion is necessary if it must be true, given that the statements are true.

\section{Some example problems:}

- If the letter is $\mathrm{A}$ then the number is 3 . The letter is $\mathrm{A}$.

Conclusion: The number is 3 .

$O$ YES $O$ NO

- If the letter is $D$ then the number is not 4 .

The number is 4

Conclusion: The letter is not D.
Y YES
$\mathrm{NO}$
$\bigcirc$ YES $O$ NO

- If the letter is not $\mathrm{H}$ then the number is 1 . The number is not 1 .

Condusion: The letter is $\mathrm{H}$.

$\mathrm{Y}$ YES $\mathrm{NO}$

- If the letter is $\mathrm{K}$ then the number is not 3 .

The number is not 3 .

Condusion: The letter is $\mathrm{K}$.

Evans, J., \& Handley, S. (1999). The role of negation in conditional inference. Quarterly Journal of Experimental Psychology, 52A, 739-769. 


\section{Belief Bias Syllogism Task}

Aim: To assess whether participants are able to evaluate logical syllogisms independently of their prior beliefs.

Instructions: In the following problems, you will be given two premises, which you must assume are true. A conclusion from the premises then follows. You must decide whether the conclusion follows logically from the premises or not. You must suppose that the premises are all true and limit yourself only to the information contained in the premises.

Some example problems:

- No addictive things are inexpensive.

Some cigarettes are inexpensive.

Therefore, some addictive things are not cigarettes.

$O$ YES $O$ NO

- No millionaires are hard workers.

Some rich people are hard workers.

Therefore, some millionaires are not rich people.

$O$ YES $O$ NO
- No police dogs are vicious.

Some trained dogs are vicious.

Therefore, some trained dogs are not police dogs.
O YES
$\mathrm{NO}$

- No nutritional things are inexpensive.

Some vitamin tablets are inexpensive.

Therefore, some vitamin tablets are not nutritional.
YES
$\mathrm{NO}$

Evans, J., Barston, J., \& Pollard, P. (1983). On the conflict between logic and belief in syllogistic reasoning. Memory \& Cognition, 11, $295-306$.

\section{Cognitive Reflection Task}

Aim: To assess whether participants are able to override intuitively appealing but incorrect answers to simple arithmetic problems.

Instructions: This section consists of three problems of varying difficulty. Answer as many as you can

\section{Problems:}

- A bat and ball costs $£ 1.10$ in total. The bat costs $£ 1.00$ more than the ball. How much does the ball cost? ...........pence.

- If it takes 5 machines 5 minutes to make 5 widgets, how long would it take 100 machines to make 100 widgets? ...........minutes.

- In a lake, there is a patch of lily pads. Every day, the patch doubles in size. If it takes 48 days for the patch to cover the entire lake, how long would it take for the patch to cover half of the lake? days.

Frederick, S. (2005). Cognitive reflection and decision making. Journal of Economic Perspectives, 19, 25-42 


\section{Wason Selection Task}

Aim: To assess participants' ability to analyse logical statements.

\section{Instructions:}

Four cards are placed on a table in front of you. Each card has a letter on one side and a number on the other. You can see:

\section{$\mathrm{D} \quad \mathrm{K} \quad 3$}

Here is a conjectured rule about the cards:

"if a card has a $D$ on one side, then it has a 3 on the other".

Your task is to select all those cards, but only those cards, which you would need to turn over in order to find out whether the rule is true or false.

Wason, P. C. (1968). Reasoning about a rule. Quarterly Journal of Experimental Psychology, 20, 273-281.

\section{Wason THOG Task}

Aim: To assess participants' ability to analyse disjunctive statements.

Instructions:

In front of you are four designs: a black diamond, a white diamond, a black circle and a white circle.
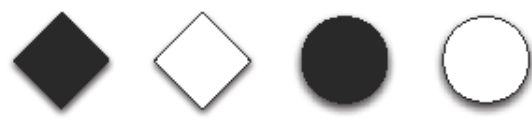

You are to assume that I have written down one of the colours (black or white) and one of the shapes (diamond or circle). Now read the following rule carefully:

If, and only if, any of the designs includes either the colour I have written down, or the shape I have written down, but not both, then it is called a THOG.

I will tell you that the black diamond is a THOG. Each of the designs can now be classified into one of the following categories: (a) definitely is a THOG; (b) insufficent information to decide; (c) definitely is not a THOG. Your task is to classify the designs:
Black Diamond
THOG
$\bigcirc$ insufficient information
not a THOG
White Diamond
THOG
$\bigcirc$ insufficient information
not a THOG
Black Circle
THOG
$O$ insufficient information
not a THOG
White Circle
THOG
$\bigcirc$ insufficient information
not a THOG

Wason, P. C. (1977). Self-contradictions. In P. Johnson-Laird \& P. C. Wason (Eds.), Thinking: Readings in Cognitive Science. Cambridge: CUP. 


\section{Argument Evaluation Task}

Aim: To assess participants' ability to evaluate arguments independently of their prior belief.

Instructions:

We are interested in your ability to evaluate counter-arguments. First, you will be presented with a belief held by an individual named Dale. Following this, you will be presented with Dale's justification for holding this particular belief. A Critic will then offer a counter-argument to Dale's justification. Finally, Dale will offer a rebuttal to the Critic's counter-argument. You are to evaluate the strength of Dale's rebuttal, regardless of your feeling about the original belief or Dale's premise. You should assume all statements are factually correct.

\section{Example Problem:}

Dale's belief: It is more dangerous to travel by air than by car.

Dale's justification: Air accidents are more likely than car accidents to involve fatalities.

Critic's counter-argument: Passengers are three times more likely to be killed per mile travelled in a car as compared to a plane.

Dale's rebuttal: Because reckless or drunk drivers cause the great majority of all automobile accidents, car travel is at least safer than air travel for people who wear safety belts and travel with sober and careful drivers.

Indicate the strength of Dale's rebuttal to the Critic's counter-argument:
Very Weak
Weak
Strong
Very Strong

Stanovich, K. E., \& West, R. F. (1998). Individual differences in rational thought. Journal of Experimental Psychology: General, 127, 161-188.

\section{Recognition of Assumptions (Watson-Glaser Critical Thinking Appraisal)}

Aim: To assess participants' ability to recognise unstated assumptions in given assertions or propositions.

Instructions: An assumption is something presupposed or taken for granted. Below are a number of statements. Each statement is followed by several proposed assumptions. You are to decide for each assumption whether a person, in making the given statement, is really making that assumption, i.e., taking it for granted, justifiably or not.

An example problem:

Statement: "The discovery of additional ways of using atomic energy will, in the long run, prove a blessing to mankind".

Proposed Assumptions:

- Atomic energy can have numerous uses.

MADE ONOT MADE

- The discovery of additional uses for atomic energy will require large long-term investments of money.

MADE ONOT MADE

- The present uses of atomic energy are a curse to mankind.
MADE
NOT MADE

Watson, G. \& Glaser, E. M. (1964). Watson-Glaser Critical Thinking Appraisal. Hardcourt, Brace \& World. 


\section{Evaluation of Arguments (Watson-Glaser Critical Thinking Appraisal)}

Aim: To assess participants' ability to discriminate between strong and weak, important and irrelevant arguments.

Instructions: In making decisions about important questions, it is desirable to be able to distinguish between strong and weak arguments. For an argument to be strong it must be both important, and directly related to the question. Below is a series of questions. Each question is followed by several arguments. You should regard each argument as true. The problem is to decide whether it is a STRONG or a WEAK argument.

An example problem:

Should groups in this country who are opposed to some of our governments' policies be permitted unrestricted freedom of press and speech?

- Yes; a democratic state thrives on free and unrestricted discussion, including criticism.

STRONG OWEAK

- No; the countries opposed to our form of government do not permit the free expression of our point of view in their territory.
STRONG
O WEAK

- No; if given full freedom of press and speech, opposition groups would cause serious internal strife and make our government basically unstable, eventually leading to the loss of our democracy.
STRONG
WEAK

Watson, G. \& Glaser, E. M. (1964). Watson-Glaser Critical Thinking Appraisal. Hardcourt, Brace \& World.

\section{Interpretation (Watson-Glaser Critical Thinking Appraisal)}

Aim: To assess participants' ability to weigh evidence and to discriminate among degrees of probable inference.

Instructions: Each problem consists of a short paragraph followed by several suggested conclusions. For the purpose of this test assume that everything in the short paragraph is true. The problem is to judge whether or not each of the proposed conclusions logically follows beyond reasonable doubt from the information given in the paragraph.

\section{An example problem:}

A Nottingham-based newspaper made a survey of the number of male and female drivers involved in all car accidents in the Nottingham area during a given period of time. They found that male drivers were involved in 1210 accidents while female drivers were involved in only 920 accidents.

- If the period studied is typical, more car accidents in the Nottingham area involve male drivers than female drivers.
FOLLOWS
DOES NOT FOLLOW

- More men than women drive cars in the Nottingham area every day.
FOLLOWS
DOES NOT FOLLOW

- Teenage boys are involved in car accidents more often than teenage girls in the Nottingham area.
FOLLOWS
DOES NOT FOLLOW

Watson, G. \& Glaser, E. M. (1964). Watson-Glaser Critical Thinking Appraisal. Hardcourt, Brace \& World. 


\section{Problem Solving}

Aim: To assess participants' ability to solve problems.

Instructions: Each problem consists of a series of matchsticks arranged to form an arithmetic statement using Roman numerals. Your task is to correct the arithmetic statement by moving a single matchstick from one position in the statement to another.

Some example problems:

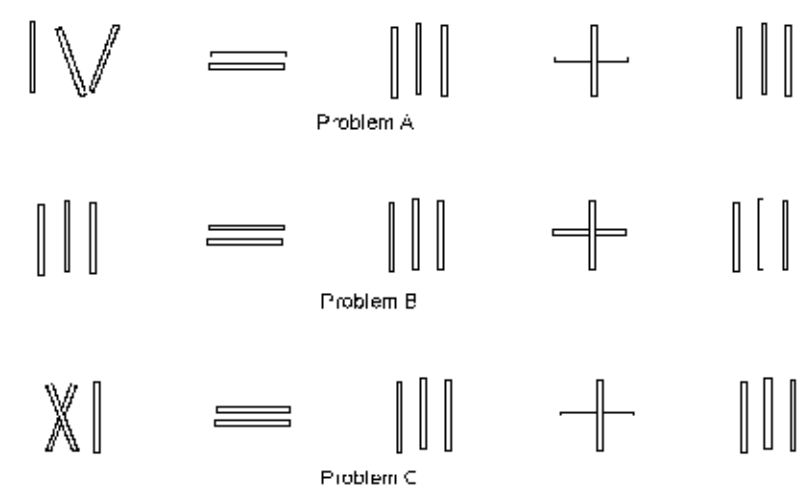

Knoblich, G., Ohlsson, S., \& Raney, G. E. (2001). An eye movement study of insight problem solving. Memory \& Cognition, 29, $1000-1009$.

\section{Plausible Estimation}

Aim: To assess participants' ability to construct plausible estimations.

\section{Example problems:}

Try to estimate reasonable answers to each of the following questions. Describe carefully at each stage any assumptions you make. Show, step by step, how you arrive at your estimate. You may assume that the population of the UK is 60 million.

- How many babies are born in the UK every minute?

- How many secondary school teachers are there in the UK?

- How many dentists are there in the UK? 


\section{Statistical Reasoning Task}

Aim: To assess participants' ability to use statistical evidence to make decisions rather than personal experience.

\section{Example Problem:}

The admissions committee of the psychology department of a midlands university was considering which 10 of 30 applicants to admit to their PhD programme. The department keeps records on the performance of all its graduate students and relates this performance score to all kinds of background information about the students. There was a debate on the admissions committee about whether to admit a particular student from the University of Maynard. The student's marks on his degree course were marginal. Almost all students previously admitted to the department had higher marks. The student's references were very good, but none of the referees were personally known to any admissions faculty. One member of the admissions committee argued against admission, pointing out that department records show that students who graduate from small non-research universities like Maynard perform at a level substantially below the median of all students in the programme. This argument was countered by a committee member who noted that 2 years ago the university had admitted a student from Maynard who was now among the three highest ranked students in the department. What do you think the committee should do?

$\bigcirc$ Definitely admit the student $\bigcirc$ Probably admit the student $\bigcirc$ Probably not admit the student Definitely not admit the student

Stanovich, K. E., \& West, R. F. (1998). Individual differences in rational thought. Joumal of Experimental Psychology: General, 127, 161-188. 


\begin{tabular}{|c|c|}
\hline $\begin{array}{l}\text { Participant } \\
\text { no. }\end{array}$ & Role in mathematics community, with affiliations \\
\hline Participant 1 & $\begin{array}{l}\text { Academic mathematician, textbook writer. } \\
\text { HEA Mathematics, Statistics and Operational Research Subject } \\
\text { Centre. }\end{array}$ \\
\hline Participant 2 & $\begin{array}{l}\text { Academic mathematician } \\
\text { Council of the Institute of Mathematics and its Applications. }\end{array}$ \\
\hline Participant 3 & $\begin{array}{l}\text { Academic mathematician, textbook writer } \\
\text { Education Committee of the Institute of Mathematicians and its } \\
\text { Applications } \\
\text { Education Committee of the London Mathematical Society. }\end{array}$ \\
\hline Participant 4 & $\begin{array}{l}\text { Academic mathematician } \\
\text { HEA Mathematics, Statistics and Operational Research Subject } \\
\text { Centre. }\end{array}$ \\
\hline Participant 5 & $\begin{array}{l}\text { Academic mathematician } \\
\text { Senior manager at a teaching focused university } \\
\text { HEA Mathematics, Statistics and Operational Research Subject } \\
\text { Centre. }\end{array}$ \\
\hline Participant 6 & Member of Parliament with an interest in education policy \\
\hline Participant 7 & $\begin{array}{l}\text { Academic mathematician } \\
\text { Senior manager at a research intensive university } \\
\text { Council of the Institute of Mathematics and its Applications. }\end{array}$ \\
\hline Participant 8 & $\begin{array}{l}\text { Academic mathematics educator } \\
\text { Council of the Institute of Mathematics and its Applications } \\
\text { Contributor to several influential reports on mathematics education }\end{array}$ \\
\hline
\end{tabular}

Table 1. Participants' roles within the mathematics education community. 


\begin{tabular}{lccccc}
\hline \multicolumn{1}{c}{ Task } & Mean (Std Dev) & Min & Max & $z$ & $p$ \\
\hline Conditional Inference & $4.75(0.46)$ & 4 & 5 & 2.64 & .008 \\
Belief Bias Syllogisms & $4.75(0.71)$ & 3 & 5 & 2.65 & .008 \\
Wason Selection Task & $4.50(0.76)$ & 3 & 5 & 2.46 & .014 \\
Plausible Estimation & $4.38(0.74)$ & 3 & 5 & 2.43 & .015 \\
Wason's THOG task & $4.25(0.71)$ & 3 & 5 & 2.43 & .015 \\
Watson Glaser Interpretation & $4.25(0.71)$ & 3 & 5 & 2.43 & .015 \\
Statistical Reasoning & $4.13(0.99)$ & 2 & 5 & 2.17 & .030 \\
Cognitive Reflection Test & $4.13(0.64)$ & 3 & 5 & 2.46 & .014 \\
Watson Glaser Assumptions & $4.00(0.76)$ & 3 & 5 & 2.27 & .023 \\
Argument Evaluation Task & $3.50(1.07)$ & 2 & 5 & 1.27 & .206 \\
Watson Glaser Evaluation & $3.38(1.01)$ & 2 & 5 & 1.00 & .317 \\
Raven's Matrices & $3.13(1.36)$ & 1 & 4 & .176 & .860 \\
Problem Solving & $2.38(1.30)$ & 1 & 5 & -1.18 & .238 \\
\hline
\end{tabular}

Table 2. Mean ratings for the extent to which studying advanced mathematics would improve performance on each task, from 1 (disagree) to 5 (agree). 


\section{The Smith Report on Post-14 Mathematics Education}

"Mathematical training disciplines the mind, develops logical and critical reasoning, and develops analytical and problem-solving skills to a high degree."

\section{The Advisory Committee on Mathematics Education}

"Skills such as problem solving abilities, perseverance and logic are highly sought after and are commonly found in those with a high level of competency in mathematics."

\section{Prof. Shimson Amitsur (Hebrew University)}

"Through mathematics we also wish to teach logical thinking — no better tool for that has been found so far."

\section{Quality Assurance Agency for Higher Education}

"Mathematics, Statistics and Operational Research graduates are rightly seen as possessing considerable skill in abstract reasoning, logical deduction and problem solving"

\section{Plato}

"Those who have a natural talent for calculation are generally quick at every other kind of knowledge; and even the dull, if they have had an arithmetical training, become much quicker than they would otherwise have been. We must endeavor to persuade those who are to be the principal men of our state to go and learn arithmetic."

Figure 1. Quotes shown to participants for discussion. 